\title{
Shifting Trend of Transient Ischemic Attack Admission and Prognosis in Canada
}

\author{
Amy Y. X. Yu, M. Patrice Lindsay, Noreen Kamal, Jiming Fang, \\ Shelagh B. Coutts, Michael D. Hill
}

\begin{abstract}
Background: Stroke is often preceded by transient symptoms. Although global stroke rates have been shown to be declining, previous studies have reported inconsistent temporal trends of transient ischemic attacks (TIA). The objective of the current study is to report the temporal trends of TIA admissions and outcomes in Canada over the last 11 years. Methods: We conducted a complete population cohort study using a national administrative database to study the temporal trend of age- and sex-adjusted TIA admission rates in Canada from 2003 to 2013. We also determined the rates of TIA and stroke diagnoses in the emergency department in the province of Ontario during the same period. We used multivariable analyses to study discharge location after acute hospitalization as well as 90-day stroke and/or TIA readmission rates. Results: Of 425,799 admissions to an acute care hospital for all stroke and TIA, 71,443 $(16.8 \%)$ were TIA. The age- and sex-standardized rates of TIA admission decreased significantly during the study period from 30.0 to 20.6 per $100,000(\mathrm{p}<0.0001)$. In Ontario, decreasing TIA admissions is mirrored by decreasing rates of TIA directly discharged from the emergency department ( 55.1 to 46.8 per $100,000, \mathrm{p}=0.002)$. The odds of 90 -day readmission rates for stroke or TIA are also decreasing (adjusted odds ratio, 0.97; 95\% confidence interval, 0.96-0.99). Conclusions: We show that TIA admission rates have declined in the past 11 years in Canada, reflecting improved vascular risk reduction and stroke care. Future studies to confirm our findings on improved stroke or TIA recurrence rates are necessary.
\end{abstract}

RÉSUMÉ: Nouvelles tendances d'hospitalisation et de pronostic de l'ischémie cérébrale transitoire au Canada. Contexte: L'accident vasculaire cérébral est souvent précédé de symptômes transitoires. Bien que les taux globaux d'AVC aient diminué, des études antérieures ont rapporté des tendances temporales inconstantes concernant l'ischémie cérébrale transitoire (ICT). Le but de cette étude était de rapporter les tendances temporales d'hospitalisation et d'issue des ICT au Canada au cours des 11 dernières années. Méthodologie: Nous avons effectué une étude de cohorte d'une population complète au moyen d'une base nationale de données administratives pour étudier la tendance temporale des taux d'hospitalisation ajustés pour l'âge et le sexe de 2003 à 2013 . Nous avons également déterminé les taux de diagnostics d'ICT et d'AVC au département des urgences dans la province d'Ontario au cours de la même période. Nous avons utilisé des analyses multivariées pour étudier le lieu du congé après une hospitalisation d'urgence ainsi que les taux d'ICT et/ou de réhospitalisation dans les 90 jours de l'incident. Résultats: Parmi les 425,799 hospitalisations dans un centre de soins aigus pour un AVC ou pour une ICT, 71,443 (16,8\%) étaient pour une ICT. Les taux d'hospitalisation pour une ICT, standardisés pour l'âge et le sexe, ont diminué significativement pendant la période de l'étude, soit de 30,0 à 20,6 par 100,000 ( $\mathrm{p}<0,0001)$. En Ontario, la diminution des hospitalisations pour une ICT se reflète dans la diminution des taux d'ICT au moment du congé directement du département des urgences (55,1 à 46,8 par 100,000; $\mathrm{p}=0,002)$. Les taux de réhospitalisation pour AVC ou ICT au cours des 90 jours suivant l'événement initial diminuent également (RC 0,97; intervalle de confiance à $95 \%$ de 0,96 à 0,99$)$. Conclusions: Nous démontrons que les taux d'hospitalisation pour ICT ont diminué au Canada au cours des 11 dernières années, reflétant une diminution du risque vasculaire ainsi qu'une amélioration du traitement de l'AVC. Des études ultérieures seront nécessaires afin de confirmer nos constatations sur les taux de récurrence de l'AVC ou de l'ICT.

Keywords: TIA, Stroke, Epidemiology

doi:10.1017/cjn.2016.305

Can J Neurol Sci. 2017; 44: 391-396

Stroke is a leading cause of mortality and morbidity globally. Recent population studies have shown a decline in stroke incidence in North America, Europe, and Asia. ${ }^{1-4}$ A significant minority (10-30\%) of ischemic stroke patients report preceding symptoms of transient ischemic attack (TIA) and they represent a target high-risk population for stroke prevention strategies. ${ }^{5-7}$

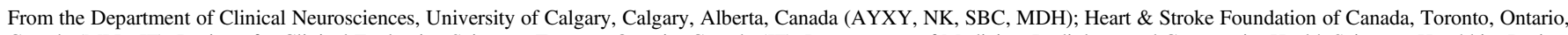
Canada (MPL, JF); Institute for Clinical Evaluative Sciences, Toronto, Ontario, Canada (JF); Departments of Medicine, Radiology and Community Health Sciences, Hotchkiss Brain Institute, University of Calgary, Calgary, Alberta, Canada (SBC, MDH).

Received December 23, 2015. Final Revisions Submitted May 23, 2016. Date of Acceptance June 23, 2016.

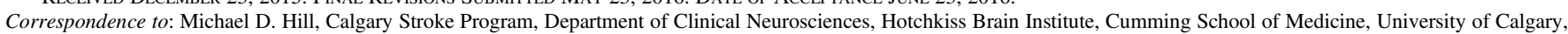
HBA 2939, Health Sciences Centre, 3300 Hospital Drive NW, Calgary, AB, T2N 4N1 Canada. E-mail: michael.hill@ucalgary.ca. 
The temporal trends of TIA are less well-understood worldwide and unknown in the Canadian population. Past epidemiological studies on incident TIA diagnosis have yielded inconsistent findings, showing increasing, ${ }^{8}$ stable, ${ }^{9,10}$ or decreasing temporal trends. ${ }^{2,11,12}$ Understanding the secular trends of TIA is an important consideration in future secondary stroke prevention studies as well as planning resource allocation after TIA. Our main objective is to study the temporal trends of TIA admissions to acute care hospitals and outcomes in Canada in the past 11 years. This period reflects the baseline just before the launch of a national stroke strategy up to the ten-year point. During this time, provinces developed their own stroke systems with variable rates of progress towards integrated stroke care by province.

We anticipate that several factors may influence the observed TIA admission rates. These include variations in disease incidence, changes in clinical practice, as well as the evolving nature of the definition of TIA. Practice changes may increase the number of TIA patients being evaluated in the emergency department and discharged to a stroke prevention clinic without hospital admission. ${ }^{13}$ Further, the diagnosis of TIA has been proposed to be changed from a time-based definition to a tissuebased one, leading to more patients being diagnosed with minor strokes instead of TIA. ${ }^{14,15}$ To assess whether changes in TIA admission rates in the past decade are truly due to decreasing TIA incidence rather than simply a reflection of clinical practice changes, we performed a subpopulation analysis in the province of Ontario to evaluate the temporal trends of TIA and stroke discharge rates from the emergency department in patients who did not have inpatient hospitalization. Ontario is the most populous Canadian province with a population of 13 million and it is the first province to have established an integrated stroke care health system. ${ }^{16}$

\section{MeTHODS}

We conducted a retrospective cohort study using an administrative database for all TIA patients admitted to a Canadian acute care hospital between 2003 and 2013 inclusive. The total Canadian population increased from 31.6 million to 35.5 million during the study period. ${ }^{16}$ All Canadian citizens and permanent residents are eligible for a publicly funded and universally available health care system, administered through the 13 provincial and territorial health insurance plans. The study excludes patients admitted to hospital without a valid provincial or territorial health insurance number, including visitors from another country and temporary workers, students, or people claiming refugee status who have not yet obtained an Interim Federal Health Program, and female patients with previous history of therapeutic abortion in accordance with privacy requirements. Data were obtained from the Canadian Institute for Health Information (CIHI). The CIHI Discharge Abstract Database (DAD) contains demographic, administrative, and discharge diagnosis data, including deaths and transfers, on all patients discharged following a hospital admission. It does not include patients who were discharged from the emergency department without inpatient admission. All hospitals are required to report to the DAD. Two exceptions are for the provinces of Manitoba, which started contributing to the DAD April 1, 2004, and Quebec, which had partial contribution during the fiscal years 2008/09 to 2011/12. ${ }^{17}$ Additionally, we also used the CIHI National Ambulatory Care Reporting System (NACRS) database. NACRS receives demographic, administrative, and discharge data for emergency departments, including discharge diagnosis mapped to International Statistical Classification of Diseases and Related Health Problems, 10th revision (ICD10-CA) codes. ${ }^{18}$ We limited the NACRS database subanalysis to the province of Ontario because all emergency departments in Ontario were mandated to report ambulatory data to NACRS throughout the entire duration of the study, whereas participation from other provinces was incomplete. Canadian administrative data have been previously shown to be valid and accurate with a specificity ranging from $88 \%$ to $99 \%$ for the diagnosis of TIA and $85 \%$ to $91 \%$ for the diagnosis of stroke using ICD-10-CA. ${ }^{19}$ TIAs were identified using ICD-10-CA code G45.x (except G45.4). Strokes were defined as any ischemic stroke, intracerebral hemorrhage, or subarachnoid hemorrhage and were identified using codes I60 (excluding 160.8), I61, I63 (excluding 163.6), I64, and H34.1. We only included patients who were coded TIA or stroke as the main diagnosis.

Our primary outcome was the trend of national TIA admission rates by year. We had multiple secondary outcomes. We evaluated the temporal trend of the age- and sex-adjusted rates of emergency department diagnosis of TIA and stroke in the province of Ontario. We also assessed the change in risk of readmission for stroke and stroke or TIA at 90 days after the initial hospital admission. Finally, we evaluated whether discharge location after acute hospitalization changed over time. Categories of discharge location include home without services, home with services (includes locations such as senior's lodge, attendant care, supportive housing and assistance such as home care health care team or meals on wheels), inpatient rehabilitation centre, long-term nursing care and/or complex continuing care, death in the hospital, or other.

\section{Statistical Methods}

We calculated age- and sex-standardized TIA admission rates using the direct method and the population from the 2011 Canadian census. Significance for trend was calculated using the Kendall rank correlation coefficient, a nonparametric test for ordered differences among classes. $\mathrm{P}$ value $<0.05$ suggests a statistically significant trend and a negative rank correlation coefficient suggests a decreasing trend over years. We used logistic regression modeling to estimate adjusted odds ratios for 90-day readmissions and multivariable Poisson regression to estimate adjusted relative risks for discharge locations. Covariates used for adjustment were age, sex, Charlson-Deyo index (0-1 vs $\geq 2$ ), and history of hypertension and atrial fibrillation. The Charlson-Deyo index is an administrative data adaptation of the Charlson comorbidity index involving a range of comorbid conditions, including vascular disease, end-organ failure, and malignancy. ${ }^{20}$ All statistical comparisons were done using SAS 9.3 (SAS Institute Inc., Cary, NC, USA).

\section{Results}

There were 425,799 stroke and TIA patients admitted to a Canadian acute care hospital from 2003 to 2013, of which 71,443 (16.8\%) were TIA. The crude number of TIA admissions by province and year are presented in Table 1. The age- and sex-standardized rates of TIA admission in Canada decreased 
Table 1: Absolute number of hospital admission for TIA in Canada by province and territories per year

\begin{tabular}{l|c|c|c|c|c|c|c|c|c|c|c}
\hline & $\mathbf{2 0 0 3}$ & $\mathbf{2 0 0 4}$ & $\mathbf{2 0 0 5}$ & $\mathbf{2 0 0 6}$ & $\mathbf{2 0 0 7}$ & $\mathbf{2 0 0 8}$ & $\mathbf{2 0 0 9}$ & $\mathbf{2 0 1 0}$ & $\mathbf{2 0 1 1}$ & $\mathbf{2 0 1 2}$ & $\mathbf{2 0 1 3}$ \\
\hline Newfoundland & 176 & 182 & 223 & 232 & 194 & 202 & 216 & 210 & 228 & 213 & 219 \\
\hline Prince Edward Island & 66 & 64 & 70 & 37 & 69 & 65 & 64 & 50 & 40 & 64 & 55 \\
\hline Nova Scotia & 255 & 282 & 239 & 182 & 186 & 203 & 205 & 213 & 221 & 189 & 165 \\
\hline New Brunswick & 362 & 411 & 395 & 393 & 346 & 319 & 298 & 294 & 308 & 291 & 346 \\
\hline Quebec & - & - & - & - & - & 1886 & 1802 & 1830 & 1863 & - & - \\
\hline Ontario & 2589 & 2753 & 2643 & 2371 & 2521 & 2484 & 2483 & 2529 & 2444 & 2613 & 2459 \\
\hline Manitoba & - & 376 & 363 & 300 & 274 & 261 & 230 & 252 & 263 & 196 & 176 \\
\hline Saskatchewan & 448 & 464 & 472 & 474 & 390 & 393 & 366 & 400 & 437 & 344 & 312 \\
\hline Alberta & 890 & 908 & 802 & 784 & 768 & 677 & 840 & 724 & 812 & 725 & 642 \\
\hline British Columbia & 981 & 964 & 979 & 918 & 940 & 951 & 1131 & 1109 & 1075 & 1060 & 1056 \\
\hline All territories & 19 & 25 & 15 & 14 & 15 & 23 & 26 & 26 & 20 & 21 & - \\
\hline Total & 5786 & 6429 & 6201 & 5705 & 5703 & 7464 & 7661 & 7637 & 7711 & 5716 & 5430 \\
\hline
\end{tabular}

from 30.0 to 20.6 per 100,000 during the study period (Figure 1; Kendall rank correlation coefficient, $0.96 ; \mathrm{p}<0.0001)$.

We linked $58,833(82.3 \%)$ TIA patients to the 90 -day follow-up data. Figure 2 illustrates the crude proportion of 90-day readmission for stroke and stroke or TIA by fiscal year. With multivariate analysis, the 90-day readmission rate for stroke remained stable (adjusted odds ratio, 0.99; 95\% confidence interval [CI], 0.97-1.00) and the combined 90-day readmission rates for stroke or TIA per year declined slightly (adjusted OR, 0.97; 95\% CI, 0.96-0.99). After acute hospitalization for TIA, patients were less likely to be discharged to a long-term care or complex continuing care institution and more likely to be discharged to their own home with additional services and support (Table 2).

In the subanalysis of TIA and stroke rates in the province of Ontario, we found a significant decrease in age- and sex-standardized rates of TIA patients discharged from the emergency department without admission. The rates dropped from 55.1 to 46.8 per 100,000 (Figure 2; Kendall rank correlation coefficient $-0.71 ; \mathrm{p}=0.002)$. Standardized rates of stroke patients discharged from the emergency department also declined from 27.5 to 17.1 per 100,000 during the study period (Figure 2; Kendall rank correlation coefficient -0.93 ; $p<0.0001$ ). Moreover, TIA rates from the combined ambulatory NACRS and inpatient

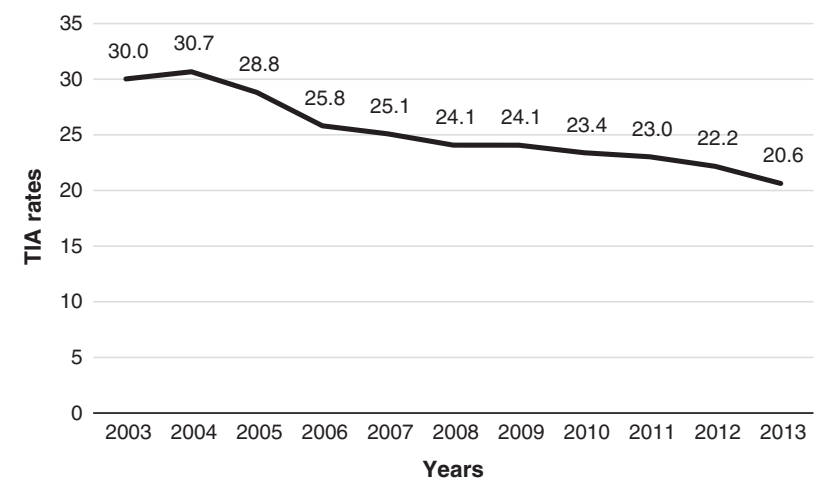

Figure 1: National age- and sex-standardized rates of TIA admission per 100,000 population by fiscal years
DAD database, reflecting both emergency department and inpatient TIA diagnoses, have also declined in the province of Ontario from 18.3 to 14.8 per 100,000 (Kendall rank correlation coefficient $-0.81, \mathrm{p}=0.005)$. Similarly, the combined emergency department and inpatient stroke rates in Ontario decreased from 112.7 to 100.2 per 100,000 (Kendall rank correlation coefficient $-0.81, \mathrm{p}=0.005$ ) (Figure 3).

\section{Discussion}

In the past 11 years, the national rates for TIA admission to an acute care hospital have declined in Canada. Our finding is consistent with other population studies from Belgium (1984-1999); Oxfordshire, United Kingdom (1981-2004); and Victoria, Australia (2001-2011) that have reported a decreasing trend in incident TIA rates, despite a general aging of the population. 2,11,12 Patients included in these studies were not necessarily admitted to an acute care hospital and cases were only included if it was an incident (first-ever) TIA. Given TIA is an episodic disease by

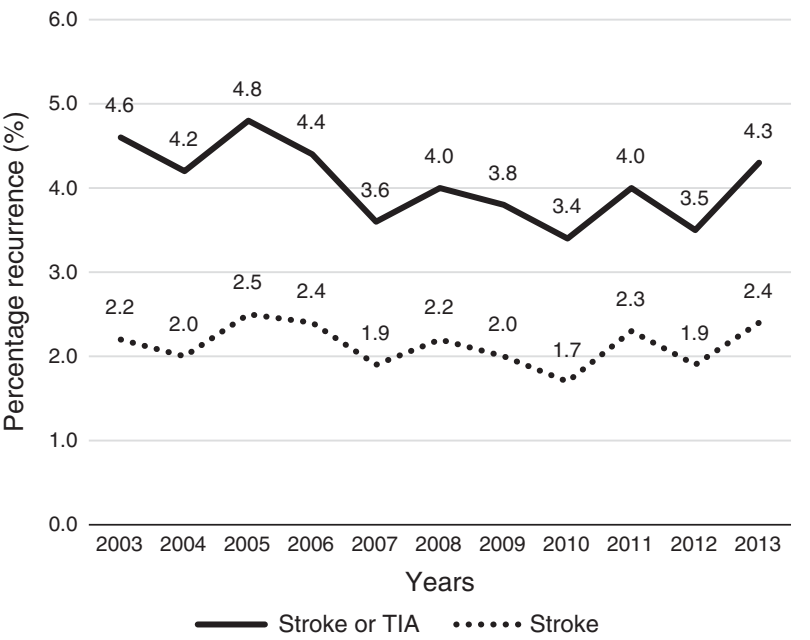

Figure 2: Crude proportion (in percentage) of 90-day readmission for stroke and stroke or TIA by fiscal years 


\section{Table 2: Adjusted relative risk per year for discharge locations after hospitalization}

\begin{tabular}{l|c}
\hline Outcome & Adjusted RR (95\% CI) \\
\hline Home without services & $1.00(0.99-1.00)$ \\
\hline Home with services & $1.03(1.02-1.03)$ \\
\hline Inpatient rehabilitation centre & $1.01(1.00-1.02)$ \\
\hline Long-term care/complex continuing care & $0.98(0.97-0.99)$ \\
\hline Death in hospital & $1.01(0.98-1.05)$ \\
\hline Discharge - Other & $0.98(0.96-1.00)$ \\
\hline
\end{tabular}

definition, we did not restrict the current study to incident cases or define a disease-free clearance period.

There are multiple explanations underlying the decreasing TIA admission rates at a national level over an 11-year period. The last decade has seen significant advances in knowledge in vascular health and patient care. Throughout the study time frame, an increased number of stroke prevention services have emerged in Canada as a result of the implementation of stroke strategies, to different degrees, in all provinces. ${ }^{21}$ Improvement in general cardiovascular risk management with antiplatelet therapy, lipidlowering agents, blood pressure, and glucose management contribute to the decrease in cerebral ischemic events. ${ }^{22-26}$ For instance, hypertension is one of the most important modifiable risk factors for stroke. Although the prevalence of hypertension is on the rise in Canada, studies have shown that its incidence is declining and that more patients are receiving the appropriate treatment to control their blood pressure. ${ }^{27,28}$ In addition, implementation of specific guidelines on carotid revascularization, anticoagulation for atrial fibrillation, and an emphasis on early evaluation times and neuroimaging may also improve secondary stroke prevention. ${ }^{29,30}$ In Canada, rates of anticoagulation for stroke prevention in context of atrial fibrillation have increased in the past decade with a concomitant decrease in stroke rates. ${ }^{31}$ Ongoing research and clinical trials may also positively impact cerebral ischemic event rates. ${ }^{32}$ Although neither of these individual reasons may be sufficient to significantly decrease TIA

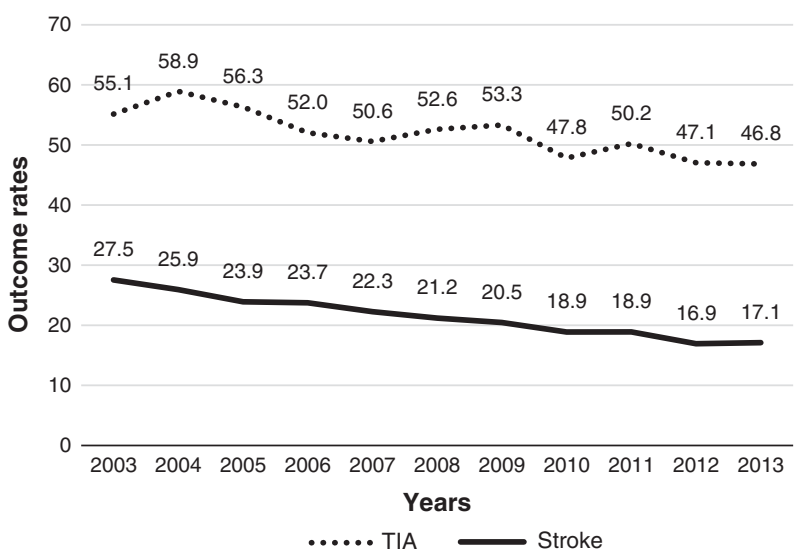

Figure 3: Age- and sex-standardized rates of TIA and stroke discharged from the emergency department in Ontario, per 100,000 population, by fiscal years admission rates, the combination of these component causes may positively influence TIA event rates.

The practice of medicine is continuously evolving, and we acknowledge that it is possible that the observed decrease in TIA admission rates is influenced by factors other than a true decrease in TIA incidence. First, our observation can result from a diagnostic ascertainment bias associated with improved neuroimaging tools and the heightened awareness of the urgency of diagnostic tests for TIA among emergency department physicians, who are often first-line in the treatment of cerebrovascular diseases. With the increasing availability of advanced neurovascular imaging, such as computed tomography angiograms and magnetic resonance imaging, physicians are more confident to exclude the diagnosis of TIA in patients with vague neurological symptoms, thus decreasing TIA rates. We think this possibility has an overall small impact on our data because we only include patients who were given the diagnosis of TIA after a complete investigation during an acute care hospital admission. Therefore, the proportion of stroke mimics in our population is expected to be small. Second, the diagnosis of TIA is shifting from a time-based definition to a tissue-based one so that patients with transient neurological deficits of vascular origin are more likely to be diagnosed as a "minor stroke" if there is imaging evidence of acute ischemia. ${ }^{14,15}$ Prior models have estimated that a tissue-based TIA definition would reduce TIA incidence by $33 \%$ with an associated rise in ischemic stroke by $7 \%{ }^{33}$ Nevertheless, instead of seeing an associated rise in stroke admissions, they have decreased in Canada during this time period. ${ }^{1}$ Third, as the urgency of TIA is being increasingly understood, more patients are expected to undergo an expedited evaluation in the emergency room or a rapid-access outpatient TIA clinic, rather than being admitted to hospital. We show that rates of TIA and stroke being diagnosed and discharged from emergency departments in Ontario without admission to hospital were also declining significantly. Our data from Ontario support the idea that the decrease in TIA hospital admissions is not completely accounted for by the secular changes in clinical practice, but rather there is a true decline in TIA admissions. Nevertheless, administrative data contain limited information from outpatient clinics. The influence of rapid-access TIA clinics on the rates of TIA admissions across Canada remains uncertain. Although the rates are declining, the burden of disease is expected to rise with the aging of the Canadian population. From a clinical perspective, clinicians should be encouraged by the declining rates of TIA admission to continue routinely practicing vascular risk reduction strategies: diagnosing and treating diabetes, hypertension, and dyslipidemia, as well as discussing lifestyle modifications including smoking cessation, exercising, and observing a salt-reduced diet. ${ }^{29}$

Our data suggest that outcomes after TIA may also be improved. The 90-day readmission rates for stroke or TIA is on a decreasing trend and TIA patients are less likely to be discharged to a nursing home after their acute hospitalization. However, these results must be interpreted with caution because the magnitude of the associations found is small and with our large sample size, we may have identified a statistical difference that may not translate into a clinically relevant finding.

An important strength of our study is that we used a national administrative database to follow a large, complete population for more than a decade in Canada. We acknowledge that administrative data are subject to hospital and jurisdiction-based coding 
variation because Canadian health care is administered by the individual provinces. By including only admitted patients, we make our case ascertainment more accurate and homogenous. Moreover, Canadian administrative data have been shown to be highly clinically accurate. ${ }^{19}$ Nevertheless, exceptions in accessing CIHI administrative data from Quebec leaves a gap in our data, which may affect the results. When examining the complete dataset for the 4 years where we have data from Quebec, we extrapolate that our results would be similar to those reported here if they were included. We used hospital discharge administrative database, which only captures patients admitted to an acute care hospital. Patients diagnosed with TIA in the emergency department, a rapid-access TIA clinic, or a primary care physician office are not fully captured by our study. This means that we have captured a high-risk population as these are the patients who require hospital admission. In addition, we obtained a partial perspective on TIA diagnosis in the Ontario emergency department. Finally, the administrative data used did not contain neuroimaging information. Thus, we were unable to ascertain the timing, frequency, and results of advanced neurovascular imaging, such as magnetic resonance imaging or computed tomography angiogram.

\section{ConClusions}

In conclusion, we show a decline in TIA admission rates to acute care hospital in Canada over an 11-year period. Although we recognize that the secular trends in clinical practice in medicine may influence TIA admission rates over time, we present arguments that our findings reflect a true improvement in vascular health and stroke care in Canada. Future studies dedicated to outcomes after TIA are necessary to further study recurrent ischemic event rates and disability after TIA.

\section{Statement of Authorship}

AYXY, NK, and MDH contributed to the study concept and design, data interpretation, and drafted and provided critical revision to the manuscript. MPL and JF contributed to the data collection, analysis, and interpretation and provided critical revision to the manuscript. SBC contributed to the data interpretation and provided critical revision to the manuscript.

\section{Disclosures}

The authors do not have anything to disclose.

\section{REFERENCES}

1. Kamal N, Lindsay MP, Cote R, Fang J, Kapral MK, Hill MD. Ten-year trends in stroke admissions and outcomes in Canada. Can J Neurol Sci. 2015;42:168-75.

2. Rothwell PM, Coull AJ, Giles MF, et al. Change in stroke incidence, mortality, case-fatality, severity, and risk factors in Oxfordshire, UK from 1981 to 2004 (Oxford Vascular Study). Lancet. 2004;363:1925-33

3. Kubo M, Kiyohara Y, Ninomiya $\mathrm{T}$, et al. Decreasing incidence of lacunar vs other types of cerebral infarction in a Japanese population. Neurology. 2006;66:1539-44.

4. Jung KH, Lee SH, Kim BJ, Y, et al. Secular trends in ischemic stroke characteristics in a rapidly developed country: results from the Korean Stroke Registry Study (secular trends in Korean stroke). Circ Cardiovasc Qual Outcomes. 2012;5:327-34.
5. Rothwell PM, Warlow CP. Timing of TIAs preceding stroke: time window for prevention is very short. Neurology. 2005;64:817-20.

6. Hill MD, Yiannakoulias N, Jeerakathil T, Tu JV, Svenson LW, Schopflocher DP. The high risk of stroke immediately after transient ischemic attack: a population-based study. Neurology. 2004;62:2015-20.

7. Johnston SC, Gress DR, Browner WS, Sidney S. Short-term prognosis after emergency department diagnosis of TIA. JAMA. 2000;284:2901-6.

8. Kleindorfer D, Panagos P, Pancioli A, et al. Incidence and short-term prognosis of transient ischemic attack in a populationbased study. Stroke. 2005;36:720-3.

9. Brown RD Jr, Petty GW, O'Fallon WM, Wiebers DO, Whisnant JP. Incidence of transient ischemic attack in Rochester, Minnesota, 1985-1989. Stroke. 1998;29:2109-13.

10. Lemesle M, Milan C, Faivre J, Moreau T, Giroud M, Dumas R. Incidence trends of ischemic stroke and transient ischemic attacks in a well-defined French population from 1985 through 1994. Stroke. 1999;30:371-7.

11. Buntinx F, Devroey D, Van Casteren V. The incidence of stroke and transient ischaemic attacks is falling: a report from the Belgian sentinel stations. Br J Gen Pract. 2002;52:813-7.

12. Sundararajan V, Thrift AG, Phan TG, Choi PM, Clissold B, Srikanth VK. Trends over time in the risk of stroke after an incident transient ischemic attack. Stroke. 2014;45:3214-8.

13. Lavallee PC, Meseguer $\mathrm{E}$, Abboud $\mathrm{H}$, et al. A transient ischaemic attack clinic with round-the-clock access (SOS-TIA): feasibility and effects. Lancet Neurol. 2007;6:953-60.

14. Albers GW, Caplan LR, Easton JD, et al. Transient ischemic attack-proposal for a new definition. N Engl J Med. 2002;347: 1713-6.

15. Sacco RL, Kasner SE, Broderick JP, et al. An updated definition of stroke for the 21st century: a statement for healthcare professionals from the American Heart Association/American Stroke Association. Stroke. 2013;44:2064-89.

16. Statistics Canada. Table 051-0001 - Estimates of population, by age group and sex for July 1, Canada, provinces and territories. URL: http://www5.statcan.gc.ca/cansim/a26?lang=eng\&id=510001.

17. Discharge Abstract Database (DAD) Metadata Available from https://www.cihi.ca/en/types-of-care/hospital-care/acute-care/ dad-metadata.

18. National Ambulatory Care Reporting System (NACRS) Metadata, 2016. Available from https://www.cihi.ca/en/types-of-care/ hospital-care/emergency-and-ambulatory-care/nacrs-metadata.

19. Kokotailo RA, Hill MD. Coding of stroke and stroke risk factors using international classification of diseases, revisions 9 and 10. Stroke. 2005;36:1776-81.

20. Deyo RA, Cherkin DC, Ciol MA. Adapting a clinical comorbidity index for use with ICD-9-CM administrative databases. J Clin Epidemiol. 1992;45:613-9.

21. 2014 Stroke Report, 2014. Available from http://www.heartandstroke. com/atf/cf/\%7B99452D8B-E7F1-4BD6-A57D-B136CE6C95BF\% 7D/HSF_SMReport2014E_Final.pdf.

22. Sacco RL, Diener HC, Yusuf S, et al. Aspirin and extended-release dipyridamole versus clopidogrel for recurrent stroke. N Engl J Med. 2008;359:1238-51.

23. Wang Y, Wang Y, Zhao X, et al. Clopidogrel with aspirin in acute minor stroke or transient ischemic attack. $\mathrm{N}$ Engl $\mathrm{J}$ Med. 2013;369:11-9.

24. Amarenco P, Bogousslavsky J, Callahan A 3rd, et al. High-dose atorvastatin after stroke or transient ischemic attack. N Engl J Med. 2006;355:549-59.

25. PROGRESS Collaborative Group. Randomised trial of a perindoprilbased blood-pressure-lowering regimen among 6,105 individuals with previous stroke or transient ischaemic attack. Lancet. 2001;358:1033-41.

26. ADVANCE Collaborative Group, Patel A, MacMahon S, Chalmers $\mathrm{J}$, , et al. Intensive blood glucose control and vascular outcomes in patients with type 2 diabetes. N Engl J Med. 2008; 358:2560-72.

27. Robitaille C, Dai S, Waters C, et al. Diagnosed hypertension in Canada: incidence, prevalence and associated mortality. CMAJ. 2012;184:E49-56. 
28. McAlister FA, Wilkins K, Joffres M, Leenen FH, Fodor G, Gee M, et al. Changes in the rates of awareness, treatment and control of hypertension in Canada over the past two decades. CMAJ. 2011;183:1007-13.

29. Coutts SB, Wein TH, Lindsay MP, Buck B, Cote R, Ellis P, et al. Canadian Stroke Best Practice Recommendations: secondary prevention of stroke guidelines, update 2014. Int J Stroke. 2014 Dec 23.

30. Kernan WN, Ovbiagele B, Black HR, et al. Guidelines for the prevention of stroke in patients with stroke and transient ischemic attack: a guideline for healthcare professionals from the American Heart Association/American Stroke Association. Stroke. 2014; 45:2160-236
31. Patel AD, Tan MK, Angaran P, et al. Risk stratification and stroke prevention therapy care gaps in Canadian atrial fibrillation patients (from the Co-ordinated National Network to Engage Physicians in the Care and Treatment of Patients With Atrial Fibrillation chart audit). Am J Cardiol. 2015;115:641-6.

32. Hong KS, Yegiaian S, Lee M, Lee J, Saver JL. Declining stroke and vascular event recurrence rates in secondary prevention trials over the past 50 years and consequences for current trial design. Circulation. 2011;123:2111-9.

33. Ovbiagele B, Kidwell CS, Saver JL. Epidemiological impact in the United States of a tissue-based definition of transient ischemic attack. Stroke. 2003;34:919-24. 